\title{
QUALIDADE DE VIDA E AMBIENTAL: A busca por centros urbanos sustentáveis
}

\author{
Luiz Vagner da Silva Junior \\ Pós-graduado em Educação Ambiental - Centro Universitário Internacional (UNINTER) \\ luizvagnersj@yahoo.com.br
}

\section{Resumo}

Nos últimos anos observa-se a ampliação da preocupação dos temas relacionados ao modo de vida nos centros urbanos. O presente artigo procura apresentar através de estudos bibliográficos, que com a criação de centros urbanos sustentáveis poderemos alcançar uma melhora na qualidade de vida e ambiental dos cidadãos. Para se chegar a tal melhoria acredita-se que seja necessário a busca pela conscientização dos cidadãos, do meio acadêmico, gestores públicos, pessoas ligadas a movimentos relacionados ao tema e políticos, fornecendo-lhes uma vasta gama de opiniões, definições, suposições e um maior aprofundamento a respeito da evolução do modo de se pensar uma cidade e suas peculiaridades. A busca por reflexões e definições sobre sustentabilidade urbana, qualidade de vida e ambiental cercam-se como objetivo principal deste estudo, buscando evidenciar que a reversão do atual sistema e a conciliação dos termos urbano e sustentável deve partir da mudança de postura e princípios de toda a sociedade, e deve iniciar-se em nós mesmos.

Palavras-chave: Qualidade de vida e ambiental. Centros urbanos. Sustentável.

\section{QUALITY OF LIFE AND ENVIRONMENTAL: THE SEARCH FOR SUSTAINABLE URBAN CENTERS}

\begin{abstract}
In recent years there has been the expansion of concern issues related to the way of life in urban centers. This article presents through bibliographical studies that with the creation of sustainable urban centers can achieve an improvement in quality of life and environmental citizens. To achieve this improvement is believed to be necessary to search for the awareness of citizens, academia, policy makers, persons related to movements related to the subject and politicians, providing them a wide range of opinions, definitions, assumptions and further deepening on the evolution of the way of thinking a city and its peculiarities. The search for ideas and definitions of urban sustainability, quality of life and environmental surround themselves as the main aim of this study in order to enhance the reversal of the current system and the reconciliation of urban and sustainable way must be from the posture change and principles of all society, and must begin in ourselves.
\end{abstract}

Keywords: Quality of life and environment. Urban centers. Sustainable. 


\section{Introdução}

A busca por uma melhor qualidade de vida e ambiental é um tema discutido não só no meio acadêmico, mas também em outros setores da sociedade que procuram se estruturar na busca por uma melhor condição de vida e ambiental. Com as mudanças ocorridas na urbanização brasileira a partir do ano de 1950, onde tivemos a saída gradual das famílias da zona rural para zona urbana, passou a perceber-se grandes aglomerações nas cidades brasileiras, que em muitas destas, não ocorreram de forma sustentável e ordenada, criando a necessidade de novos processos e padrões de desenvolvimento urbano.

Mas como podemos reverter e criar novos processos e padrões para tal situação? Como devemos agir para termos nos centros urbanos uma melhora significativa na qualidade de vida e ambiental de nossos cidadãos? Como podemos fazer caminhar juntos os termos urbano e sustentável?

Não é de interesse deste trabalho discutir questões como, a criação de áreas verdes ou saneamento, por exemplo, que, apesar de estarem ligadas à problemática ambiental urbana e interferirem na qualidade de vida dos cidadãos, ultrapassam as reflexões de análise do presente momento.

Este artigo tem como objetivo buscar reflexões e definições sobre o meio ambiente urbano, qualidade de vida e ambiental e chegar a comprovação de que com a criação de centros urbanos sustentáveis e a mudança de postura da sociedade, teremos uma melhora significativa na qualidade de vida e ambiental dos cidadãos, podendo auxiliar em futuras discussões e proposições, que agregue na conscientização de gestores públicos, políticos e pessoas ligadas a movimentos que compartilhem da mesma ideia e também o meio acadêmico, se tornando material para posteriores estudos e conscientização de toda a sociedade.

\section{A Construção da Qualidade de Vida e Ambiental nos Centros Urbanos}

\section{A busca por definições}

Pode-se dizer que os grandes movimentos em prol do meio ambiente de forma global passaram a ser percebidos no ano de 1968 com a criação do clube de Roma na Academia Dei Lincei, em Roma, por cientistas de diversos países, na tentativa de se criar soluções para os 
problemas decorrentes do grande crescimento demográfico que já causava certo desequilíbrio sobre os ecossistemas do planeta.

No ano de 1972, de 5 a 16 de junho, aconteceu a Conferência de Estocolmo, que destacando os problemas da pobreza e o crescimento da população, elaborou metas ambientais e sociais centrando a sua atenção nos países em via de desenvolvimento, fazendo com que a Conferência fosse marcada por acaloradas discussões sobre meio ambiente versus desenvolvimento.

Em Dezembro de 1989, a Assembleia Geral das Nações Unidas convocou um encontro global para elaborar estratégias de reversão dos processos de degradação ambiental. A resposta a essa convocação foi dada através da Agenda 21, adotada pela Conferência das Nações Unidas sobre Meio Ambiente e Desenvolvimento, em Junho de 1992, no Rio de Janeiro, ficou conhecida como "Cúpula da Terra” e também “ECO 92”. Onde, posteriormente se elaborou um relatório tratando questões ligadas ao suprimento de água, serviços sociais, educativos e sanitários e também de administração do crescimento urbano (CNUMAD, 1996).

Duas décadas após a Rio-92, novamente no Rio de Janeiro, no encontro intitulado Rio +20, 193 países se encontraram pretendendo apontar novos caminhos para a mudança nas relações do homem com a natureza. Ao final do encontro redigiu-se um documento com o título - “O futuro que queremos". (CNUMAD, 2012)

Para os otimistas ligados ao movimento ambiental, o encontro foi um sucesso ao se referir ao avanço do conceito de desenvolvimento sustentável. Já os pessimistas presentes esperavam maiores medidas de ordem prática para garantir um desenvolvimento sustentável mais efetivo.

\section{Qualidade de vida e ambiental}

Em relação a qualidade de vida e ambiental de um centro urbano, podemos considerar o assunto com grande amplitude, pois o que se tem é a existência de vários índices e indicadores, tanto qualitativos quanto quantitativos como forma para definição de tais termos.

Segundo Oliveira (2003):

Mesmo sendo complexo estabelecer padrões de qualidade de vida e ambiental, pode-se recorrer à percepção, fator imprescindível para determinar a qualidade ambiental e de vida. As condições de qualidade ambiental são muito subjetivas e serão boas ou más de acordo com o tipo e 
situação da população em questão, e de como ela se relaciona e percebe o meio ambiente e a vida.

Troppmair (1995) também afirma que: “A sadia ou boa qualidade de vida é definida pelos parâmetros físicos, químicos, biológicos e sociais que permitem o desenvolvimento harmonioso, pleno e digno da vida".

$\mathrm{O}$ autor trata o assunto de forma sucinta e direta, destacando que os fatores físicos, químicos e biológicos são elementos que veem influir de forma direta e indireta na saúde humana (luminosidade, umidade, temperatura, etc.), já os parâmetros sociais são apresentados pelas adversidades vividas que provocam alterações no comportamento humano.

Já, ( MACHADO, 1993, p. 54) destaca:

"A qualidade de vida representa algo mais do que um padrão de vida. Envolve, entre outras coisas, a disponibilidade máxima de infraestrutura pública e social para proporcionar o bem para manter o meio ambiente sem deterioração e contaminação significativas. A qualidade de vida também requer muitos fatores inter-relacionados, a maioria dos quais não quantificáveis, que ajudem a satisfazer os desejos e as aspirações, da mesma forma que as necessidades humanas".

Ao se tratar qualidade ambiental utilizando o termo "quantificáveis" a autora propõe trabalhar com a abordagem quantitativa, que representa os padrões de qualidade, que são representados através de indicadores do desenvolvimento mundial obtidos pelo Banco mundial, como renda per capta, expectativa de vida ao nascer, analfabetismo entre adultos, etc. e por indicadores Municipais, econômicos, financeiros, infraestrutura de serviços e indicadores sociais. Também propõe a utilização de indicadores qualitativos, perceptíveis, baseado no estudo da cidade como fenômeno experênciado pelo morador.

Os altos ou baixos índices de qualidade de vida e qualidade ambiental estão diretamente ligados à forma que os órgãos gestores administram a cidade, pois, com recursos financeiros e ambientais, garantidos pela Lei de Diretrizes Orçamentárias do Município (LDO), com planejamento urbano, que pode estar embasado na elaboração de um "Plano Diretor Municipal" na busca por uma melhor condição para a população. Desta forma teremos, tanto os indicadores quantitativos quanto os qualitativos para suprir as necessidades de toda a população. Tem-se a boa ou a má qualidade ambiental em nossas mãos e consciência, através de nossa percepção ou modo de vermos o ambiente. 
Devemos sim mudar nosso relacionamento com o local em que vivemos, mas, devemos também nos atentar a assistência que os órgãos públicos podem nos dar, pois, se os órgãos gestores não se relacionarem de forma responsável e ativa, a população também não irá se relacionar e perceber o meio ambiente e a vida de maneira diferenciada.

Realmente percebe-se em toda a sociedade uma acomodação em relação à mudança de postura, quanto a sua vida e ao ambiente, todos exigem mudanças, mas poucos se dispõem a cobrar e a viver essas mudanças de forma efetiva. Temos como exemplo a cidade de Curitiba (PR), que apresenta bons índices de qualidade de vida e ambiental, fruto da organização e planejamento de seus governantes e de sua população.

Segundo a SMMA (Secretaria Municipal de Meio Ambiente) da cidade de Curitiba $(\mathrm{PR})$ :

Considera a Educação ambiental como uma forma de integrar as ações do poder público e da população, para que juntos, possam construir um ambiente equilibrado para viver. As questões ambientais são tratadas sempre com o objetivo de resgatar a história da cidade e manter a identidade dos moradores com o meio em que vivem possibilitando a incorporação de valores relativos à proteção ambiental aliada à sustentabilidade do desenvolvimento local.

Observa-se assim a importância de se conciliar o poder público e sua população, de forma que se possa conscientizar e trabalhar em conjunto com os cidadãos as questões que o envolvem e possam vir a interferir sobre as gerações futuras, criando um convívio harmonioso ao se tratar o meio ambiente urbano e a qualidade de vida e ambiental de seus moradores, oferecendo-lhes propostas e projetos que possam vir melhorar seu dia a dia, criando uma mudança de postura e conceitos.

\section{Os centros urbanos}

Já ao se conceituar o urbano, como cidade, devemos sempre levar em consideração o ser humano, em sua totalidade, com a ordenação dos espaços onde mantem e desenvolve suas atividades e a qualidade que se obtém das relações estabelecidas através destes elementos em seu meio de convívio.

No que se refere a formação do ambiente urbano temos problemas que, por vezes, são peculiares, cujos processos de resolução lhes são próprios, os quais demandam políticas e priorizações para o alcance de uma cidade saudável, a qual se apresenta por um 
desenvolvimento social, que tem a saúde e suas múltiplas determinações como centro de atenções, e envolve um movimento de luta por um estilo de desenvolvimento sustentável. (WESTPHAL, 2000, p. 42).

Carlos (1997) afirma que, "Deve-se aqui lembrar que a cidade tem a dimensão do humano refletindo e reproduzindo-se através do movimento da vida, de um tempo específico que tem na base o processo de construção humana.” (CARLOS, 1997, p.61)

Pierre George (1983), analisa e define a cidade, envolvendo uma perspectiva histórica, onde:

A cidade em cada época, um produto que não se limita a exercer sua influência sobre as únicas aglomerações urbanas, pois a cidade vai se reestruturando na medida em que a sociedade se modifica. Assim, em cada uma entre inúmeras etapas do processo histórico, a cidade assume formas e características distintas. Nessa perspectiva, no meio ambiente urbano há a necessidade de integração das políticas públicas como, por exemplo, as políticas públicas de habitação, de saneamento ambiental e a própria política ambiental.

No Brasil, observa-se a intensificação da urbanização a partir de 1950, principalmente com o advento da indústria nacional, que serviu como atrativo para o estabelecimento de um grande contingente populacional nas cidades, em busca de trabalho e melhores condições de vida. Esse ritmo de crescimento urbano verificado no país após 1950 é justificado por Santos (1993) quando afirma que:

A aceleração da urbanização a partir da Segunda Guerra Mundial é concomitante ao crescimento demográfico brasileiro registrado nessa época, que resultou em grande parte de um decréscimo na mortalidade devido aos progressos sanitários, a melhoria relativa nos padrões de vida e à própria urbanização (SANTOS,1993, p.31).

Na história brasileira uma regulação federal, para as políticas urbanas, definindo uma ocupação de intervenção no território, após anos de debates, foi aprovado no Congresso Nacional o Estatuto da Cidade. A função deste estatuto é garantir o cumprimento da função social da cidade, o que implica no estabelecimento de normas de ordem pública e interesse social, que regulam o uso da propriedade urbana, em prol do bem coletivo.

O Estatuto da Cidade coloca à disposição dos municípios uma série de instrumentos, que podem intervir no mercado de terras e nos mecanismos de produção da exclusão. Dentre 
eles, uma nova estratégia de gestão, que incorpora a ideia de participação direta da sociedade, em processos de decisões sobre o destino da cidade.

\section{A Busca por Soluções}

\section{A educação ambiental}

No que se refere a educação ambiental e sustentabilidade, observa-se que tais termos exercem um papel de transformação em nossa sociedade, fazendo com que o cidadão de forma individualizada passe a buscar novas soluções e alternativas na busca pelo desenvolvimento sustentável.

No que se refere aos conceitos, definições e opiniões sobre a educação ambiental, destacam-se grandes encontros ocorridos nas últimas décadas, dentre eles destaca-se o de Tbilisi, onde:

Destaca-se que a Educação Ambiental deve considerar o meio ambiente em sua totalidade, em seus aspectos naturais e aqueles criados pelo homem. Enquanto processo contínuo e permanente a Educação Ambiental, deve atingir todas as idades e níveis do ensino formal e não formal; deve examinar as questões ambientais do ponto de vista local, regional, nacional e internacional, analisando suas causas, consequências e complexidade. Deve ser dirigida à comunidade despertando o interesse do indivíduo em participar de um processo ativo no sentido de resolver os problemas dentro de um contexto de realidades específicas, estimulando a iniciativa, o senso de responsabilidade e o esforço para construir um futuro melhor (DIAS, 1994).

A educação ambiental tem como objetivo, portanto, formar a consciência dos cidadãos e transformar-se em filosofia de vida de modo à levar a adoção de comportamentos ambientalmente adequados, investindo nos recursos e processos ecológicos do meio ambiente. A educação ambiental, deve necessariamente transformar-se em ação.

Para se conseguir esta mudança de paradigma entres os cidadãos, deve se levar em conta a grande dificuldade a ser enfrentada, pois em grande parte dos centros urbanos em todo o mundo se mantem o sistema econômico capitalista, que não enxerga com bons olhos tal mudança, levando a transformação do modo de vida de toda a sociedade a ser considerada utopia. 
Tem-se deste modo que a educação ambiental deve ser considerada como um processo puramente educativo, buscando transformar a base de nossa sociedade até seu topo, ou seja, alicerçar-se nas crianças passando por adultos chegando aos idosos, pregando valores éticos e ambientais.

\section{O papel do cidadão}

Ao se tratar problemas de desenvolvimento sustentável, qualidade de vida e ambiental diante a comunidade, percebe se que a busca por sua solução deve iniciar-se com a participação ativa de cidadãos com maior nível de informação e que estejam dispostos a aceitar e contribuir com novos modos de vida, que procurem conhecer as realidades em diferentes escalas, fazem relações entre assuntos como sociedade, economia e meio ambiente e entre a vida da sua comunidade urbana e de outras comunidades, levando em conta as necessidades e direitos das gerações atuais e futuras.

Segundo ACCAC, 2002 apud Ferreira os conceitos-chave do "desenvolvimento sustentável" que todos os cidadãos devem conhecer são os seguintes:

- Interdependência - reconhecer que as populações, o ambiente e a economia são inextrincavelmente ligados a todos os níveis, do local ao global;

- Cidadania - reconhecer a importância de se responsabilizar e de desenvolver atividade individual para fazer do mundo um lugar melhor;

- Necessidades e Direitos - compreender as suas próprias necessidades básicas e os direitos humanos e as implicações das ações tomadas hoje em relação às necessidades das gerações futuras;

- Diversidade - compreender, respeitar e valorizar a diversidade humana cultural, social e econômica - e a biodiversidade;

- Mudanças sustentáveis - entender que os recursos são finitos e que isto tem implicações para os estilos de vida das populações e para as atividades ligadas ao comércio e à indústria;

- Bem-estar - reconhecer que a equidade e a justiça globais são elementos essenciais do desenvolvimento sustentável e que as necessidades básicas devem ser universalmente satisfeitas;

- Incerteza e precaução - reconhecer que há uma variedade de vias possíveis para o desenvolvimento sustentável e para a cidadania global e que as situações estão a alterar-se constantemente, donde resulta uma necessidade de flexibilidade e aprendizagem ao longo da vida.

- Valores e percepções - necessidade de realizar uma avaliação crítica de imagens e da informação acerca das partes do mundo menos e mais economicamente desenvolvidas, e de compreender o efeito das imagens e da informação nas atitudes e nos valores individuais.

- Resolução de conflitos - entender como os conflitos constituem uma barreira para o desenvolvimento e um perigo para todos e ainda porque razão há necessidade de os resolver e de promover uma harmonia entre os povos. 
Luiz Vagner da Silva Junior

Existe ainda um conjunto de habilidades, atitudes e valores que os cidadãos devem desenvolver:

- Habilidades:

- Espírito crítico

- Capacidade de discussão

- Capacidade de desafiar a injustiça e as desigualdades

- Respeito pelas pessoas e pelas coisas

- Sentido de cooperação e de resolução de conflitos

- $\quad$ Valores e atitudes:

- Sentido de identidade e de auto estima

- Interesse pelos outros

- Preocupação com a justiça e a equidade sociais

- Valorização e respeito pela diversidade

- Preocupação com o ambiente e empenhamento pelo desenvolvimento sustentável

- Crença de que os indivíduos podem fazer a diferença.

- Um cidadão do século XXI deve possuir as seguintes características:

- A capacidade de abordar problemas como um membro de uma sociedade global;

- A capacidade de trabalhar de uma forma cooperativa com outros e tomar a responsabilidade pelos seus deveres e direitos em relação à sociedade;

- A capacidade de compreender, aceitar, apreciar e tolerar diferenças culturais;

- A capacidade de pensar de um forma crítica e sistemática;

- A disponibilidade em resolver conflitos de uma forma não violenta;

- A disponibilidade em alterar o estilo de vida e hábitos de consumo para proteger o ambiente;

Temos assim a busca pela construção de uma ideia que está embasada em uma série de conceitos, habilidades, valores e atitudes em que a mudança depende de nossa capacidade em interagir com o meio e modifica-lo, transformando-o em instrumento de apoio de nosso cotidiano no ambiente urbano. Ambiente este que na maioria do tempo passamos pedindo aos governantes algum tipo de melhora, sempre acomodados em nossa "zona de conforto", não estando dispostos a buscar novas formas de interagir com a cidade.

\section{A busca por um modelo de cidade sustentável}

A construção do projeto de cidades sustentáveis vem sendo buscada através de uma série de indagações e da aplicação e manutenção de boas práticas que, em sua concepção, 
buscam considerar diversos níveis de preocupação com a situação ambiental local e global e os tempos presente, passado e futuro.

Emelianoff apud Magalhães (2006) cita que:

\begin{abstract}
Ao analisar a rede de cidades sustentáveis, que se formou a partir dos encontros de Aalborg, em maio de 1994, que constituiu uma rede de 67 cidades europeias e de Manchester, em junho de 1994, que reuniu outras 50 cidades em escala internacional, observa que essas cidades parecem trabalhar em três frentes, tratando a cidade como: a cidade ecossistêmica, a patrimonial e a participativa.
\end{abstract}

A busca pela aptidão da cidade deve ser elemento chave na busca por um centro urbano com qualidade, pois desta forma poderá se analisar os problema em sua raiz, identificando e aplicando ações mitigadoras conforme seja necessário. A cidade ecossistêmica é do interesse das cidades industriais dentre os problemas a serem solucionados ou evitados teremos aspectos relacionados a reciclagem de seus rejeitos e camada de ozônio, que são efeitos da poluição. A cidade patrimonial é liderada por cidades que já identificaram um patrimônio natural ou cultural, cidades históricas ou turísticas, que estão mais preocupadas com o estético de sua malha urbana, seus espaços públicos e a criação de um ambiente natural, cultural e social no convívio com o meio urbano. Já cidade participativa é almejada por cidades que desejam reconstruir sua identidade comunitária, sua dinâmica urbana, criando uma maior proximidade daqueles que residem ou trabalham na cidade através de parcerias e estratégias que possam vir a alterar o modo de vida de seus habitantes.

A definição da aptidão da cidade como cita a autora Emelianoff, também pode ser feita através da Lei do Plano Diretor que irá definir a função social da cidade e da propriedade urbana, além de organizar o crescimento e o funcionamento do município de forma contínua e sustentável. Consiste ainda em um pacto sociopolítico da sociedade em direção a uma cidade mais humana, participativa, inclusiva e funcional, que ofereça qualidade de vida para a população. Deve apresentar uma visão de futuro para as próximas gerações, orientando o desenvolvimento de seu município de forma geral.

A ampliação do conceito de sustentabilidade criou um novo ideal de cidade, a ser atingido, ficando focado em ações direcionadas ao meio ambiente, a maior democracia e transparência da gerência e das decisões nas cidades e a redução das desigualdades.

Scandurra apud Magalhães (2006) afirma que: 
A cidade do futuro deve ser multiétnica, multirracial, cidade das crianças, das mulheres, dos habitantes, cidade-jogo, cidade do tempo liberado do trabalho, cidade dos pedestres e não das máquinas, cidade da segurança, cidade da comunicação, informação, conversação, cidade da troca entre grupos, cidade dos espaços livres, cidade da invenção e da criatividade, da inovação, da transformação, da autonomia e da autodeterminação, multicêntrica, ecológica.

A busca pelo modelo proposto soa aos nossos ouvidos como um modelo utópico, mas de certa forma ideal. Para se chegar a harmonia de todos os elementos citados o pensamento deve se tornar homogêneo e contínuo por todos os cidadãos da cidade, partindo do eu para o nós, tendo como base para tal conquista a educação, seja ela formal ou não formal.

\section{Considerações Finais}

Analisando os autores apontados e refletindo sobre seus estudos, chega-se à conclusão que a meta a ser alcançada é a de se criar um projeto de "Cidades Sustentáveis", podendo assim garantir a qualidade de vida e ambiental para os centros urbanos.

Mas para unirmos os termos urbano e sustentável devemos olhar com novos olhos as ações realizadas pela sociedade, as ações políticas e os mecanismos existentes, para assim podermos definir um conjunto de regras e princípios básicos para uma ação mais sólida e consistente, com metas a serem alcançadas e um melhor acompanhamento das ações.

A primeira ação a ser tomada deve partir da educação ambiental de toda a comunidade, fazendo com que se entenda que a busca por uma cidade sustentável irá beneficiar a todas as classes sociais e econômicas da cidade. Implantar tal consciência na comunidade é de extrema importância, tendo deste modo garantida a sustentabilidade do processo.

Outro ponto a se repensar, deve ser o sistema político, que requer maior planejamento e transparência, buscando uma série de instrumentos que estejam ligados as dimensões ambientais, sociais e econômicas tentando se criar maior conectividade e interação entre eles. Tais instrumentos irão auxiliar na busca vocacional da cidade como vimos na citação de Emelianoff apud Magalhães (2006), fazendo com que após esta definição o processo de busca pela sustentabilidade se torne mais ambicioso e com maior foco a ser alcançado, pois ao se alinhar os pensamentos se evitará políticas e estratégias contraditórias ao longo do processo.

Para conseguir se criar ou até mesmo recriar estes processos, deve se garantir um novo relacionamento com a cidade, visando conseguir se criar uma acessibilidade urbana 
sustentável, um novo ordenamento ou manutenção no que diz respeito a sua mobilidade, utilização do solo, suas áreas verdes com proteção a sua flora, fauna, rios e nascente, as atividades de lazer e turismo e ainda seu patrimônio cultural.

Para se criar o projeto de "Cidade Sustentável" deve-se apoiar na força da criatividade e da mudança de postura, onde o cidadão deverá fazer parte eminente do processo de transformação, pois o que se propõe mudar é sua qualidade de vida e ambiental. No seu relacionamento com a cidade, suas ações serão parte central neste processo de convívio, suas habilidades, valores e atitudes devem ser valorizados e aprimorados e nunca paralisados, garantindo a continuidade e melhoria da qualidade de vida e ambiental de sua geração e também das futuras.

\section{Referências}

CARLOS, Ana Fani A. A cidade. 3.ed. São Paulo: Contexto, 1997.

CNUMAD - Conferência das Nações Unidas sobre Meio Ambiente e Desenvolvimento. Agenda 21 - Brasília: Senado Federal/SSET, 1996.

CNUMAD - Conferência das Nações Unidas sobre Meio Ambiente e Desenvolvimento. Rio de Janeiro, Brasil. 2012

DIAS, G.F. Educação ambiental: princípios e práticas. São Paulo, Gaia, 1992.

FERREIRA, M.M.M.D. "Desenvolvimento Urbano Sustentável: o Papel dos Cidadãos. Universidade aberta, Lisboa, Portugal, 2005.

GEORGE, Pierre. Geografia urbana. São Paulo, Difel, 1983

MACHADO, L.M.C.P. Qualidade Ambiental Urbana: Percepções e estratégias para uma cidade de porte médio. Departamento de Geografia. IGCE/UNESP, Rio Claro, 1993.

MAGALHÃES, Roberto Anderson de Miranda. A Construção da Sustentabilidade Urbana. Brasília, III encontro ANPPAS, Maio de 2006.

OLIVEIRA, Lívia de. A percepção da qualidade ambiental. Ação do homem e a qualidade ambiental. Rio de Janeiro: ARGEO e câmara Municipal, 1983.

SANTOS, M. A urbanização brasileira. 3 ed. São Paulo: Hucitec,1993.

SMMA - Secretaria Municipal de Meio Ambiente. Educação Ambiental. Portal da Prefeitura de Curitiba. Paraná, 2014. Disponível em: www.curitiba.pr.gov.br Consultado em Julho de 2014. 
TROPPMAIR, H. Biogeografia e meio ambiente. $3^{\circ}$ ed. Rio Claro. Ed. Do autor, 1989, 258 p.

WESTPHAL, M. F. O Movimento Cidades/Municípios Saudáveis: um compromisso com a qualidade de vida. Ciência \& Saúde Coletiva. 2000, vol. 5, n.1, p. 39-51. 